Communications in Physics, Vol. 22, No. 4 (2012), pp. 375-382

\title{
STUDY, DESIGN AND CONSTRUCTION OF AN EARLY WARNING ENVIRONMENTAL RADIATION MONITORING STATION
}

\author{
DANG QUANG THIEU, TRAN NGOC TOAN, \\ NGUYEN THI BAO MY, NGUYEN VAN SY, VU VAN TIEN, \\ NGUYEN THI THUY MAI AND LE DINH CUONG \\ Institute for Nuclear Science and Technology, \\ Vietnam Atomic Engergy Institute
}

\begin{abstract}
We report on the design and construction of an Early Warning Environmental Radiation Monitoring Station (EWERMS), used ONLINE in the environmental radiation monitoring and early warning network. It has a high sensitivity and can send a prompt alarm signal via Internet to the emergency management office. It includes four gamma probes: one $\mathrm{NaI}(\mathrm{Tl})$ and three Geiger Mueller (GM) detectors. The NaI(TL) detector is used to monitor spectrum environmental radiation and measure the isotopic composition, the GM detectors are used to detect and measure high gamma ray rates. The instrument has been designed to be used outdoor and tolerate large and rapid temperature variations. The photomultiplier tubes (PMT), amplifiers and Analog To Digital $(A D C)$ gains are stabilized using pulsed LEDs as precision reference light sources.
\end{abstract}

\section{INTRODUCTION}

More and more nuclear reactors are being constructed and operated worldwide for the purpose of power generation as well as for doing research. Consequently, continuous monitoring of the ambient dose rate is an essential task that must be carried out routinely in order to provide the responsible radiation protection governmental authorities with the necessary information. This includes:

a) establishing a national data base of environmental dose rates covering the whole country;

b) in a preliminary phase, measuring and recording baseline background gamma radiation levels to be used as a reference for future surveys;

c) providing an early warning alarm in case of an important increase of the radioactivity level.

This requires the installation and operation of an array of radiation detectors (GM and/or scintillation detectors) to survey and monitor the environmental dose rate. They must be read out continuously at well defined time intervals. While the elements of such an array are relatively simple instruments, their operation as a global system, including other possible sensors aimed at providing additional information, such as weather conditions, and at improving the accuracy of the measurtement requires much care.

There exist many types of commercially available radiation detectors that can do the job but, as a very large number of these will be required, a low cost design would be 
particularly welcome. The purpose of the present paper is to discuss such a device that has been conceived as a prototype environmental radiation monitor to be used in Hanoi.

\section{DESIGN AND CONSTRUCTION}

Some radiation counters and detectors as well as nuclear instruments have been designed and constructed within our electronics department of the Institute for Nuclear Science and Technology, Hanoi, Vietnam, and sufficient experience has been gained through the postgraduate programs for teaching, training and research.

The aim of project is to design and construct a prototype unit for the monitoring of the ambient dose rate in the environment. The dose range that is considered is within the range of the dose rate of $0.01 \mu \mathrm{Sv} / \mathrm{h}$ to $50 \mathrm{mSv} / \mathrm{h}$, for the energy range of $80 \mathrm{keV}$ to $3 \mathrm{MeV}$. The expected accuracy is around $\pm 15 \%$. The unit is suitable for working in environmental conditions within the temperature range: $0^{\circ} \mathrm{C}$ to $50^{\circ} \mathrm{C}$ and relative humidity up to $95 \%$.

An online connection is a feature design of our monitoring unit to allow the connection with other units of monitoring network through LAN or Internet.

In addition, this project will enhance the capabilities for the staff in the field of design, construction and maintenance of the nuclear instruments within our institution.

The electronics department of the Institute for Nuclear Science and Technology (INST, Hanoi) has experience in designing and constructing nuclear instruments including radiation detectors, as well as in providing graduate and postgraduate training in the field.

We have designed and constructed a prototype monitoring unit of the ambient gamma ray dose rate. The dynamical range is from $0.01 \mu \mathrm{Sv} / \mathrm{h}$ to $50 \mathrm{mSv} / \mathrm{h}$ and the energy range from $80 \mathrm{keV}$ to $3 \mathrm{MeV}$. The precision is of the order of $\pm 15 \%$. The unit is suitable for working outdoor at temperatures between 0 and $50^{\circ} \mathrm{C}$ and under relative humidity of up to $95 \%$.

The unit can be read-out online, allowing for its connection with other units of the monitoring network via LAN or Internet.

\section{Hardware Design}

The design of the Early Warning Environmental Radiation Monitoring Station (EWRMS) is illustrated in Fig.1. It consists of:

\section{Detectors}

The unit uses four gamma-ray detectors; one of these is a $\mathrm{NaI}(\mathrm{Tl})$ crystal of area $1.5 " \times 1.5 "$. The other three are GM counters.

Each detector includes a high voltage generator and front-end electronics (a preamplifier for the NaI detector and pulse shaping circuits for the GM counters).

\section{Amplifier and 12 bit-ADC}

The spectrum amplifier and 12 bit-ADC are of a simple design using standard chips. The spectrum amplifier includes a preamplifier, amplifier, shaping, baseline restoring, and zero adjustment. In particular, the gain of the amplifier has been digitized and can be adjusted by a microcontroller allowing for automatic calibration and gain stabilization using a reference light source described below.

The ADC block includes a pulse stretcher, a fast ADC and a logic controller using GAL technology. 


\section{Reference light source and energy spectrum stabilization}

A light emitting diode (LED) provides a reference light source using a thin light fiber inserted between PMT photocathode and crystal. Its signal, around $4 \mathrm{MeV}$ equivalent, namely far away from the environmental spectrum, is used as a reference by the microcontroller to adjust the PMT gain.

\section{Microcontroller board}

The microcontroller uses a single-chip 8 bit unit, 89C51RD2, a derivative of the $80 \mathrm{C} 51$ family, manufactured in advanced CMOS. It contains a $1 \mathrm{kB}$ RAM and a non-volatile $64 \mathrm{kB}$ Flash program memory that is both parallel programmable and serial In-System and In-Application Programmable. The instruction set is $100 \%$ compatible with the 80C51 instruction set. The device has four 8 bit I/O, three 16 bit timer/event counters, a multisource, four-priority-level, nested interrupt structure, an enhanced UART and on-chip oscillator and timing circuits.

One MBYTE RAM is added for increased data memory capacity. Also included are a real time clock, internet connection, LCD display and DC-DC converter.

\section{Probe selection board}

A probe selection board is used to select suitable probes corresponding to the level of radioactivity. The dose ranges of the selected probes are listed in Table 1.

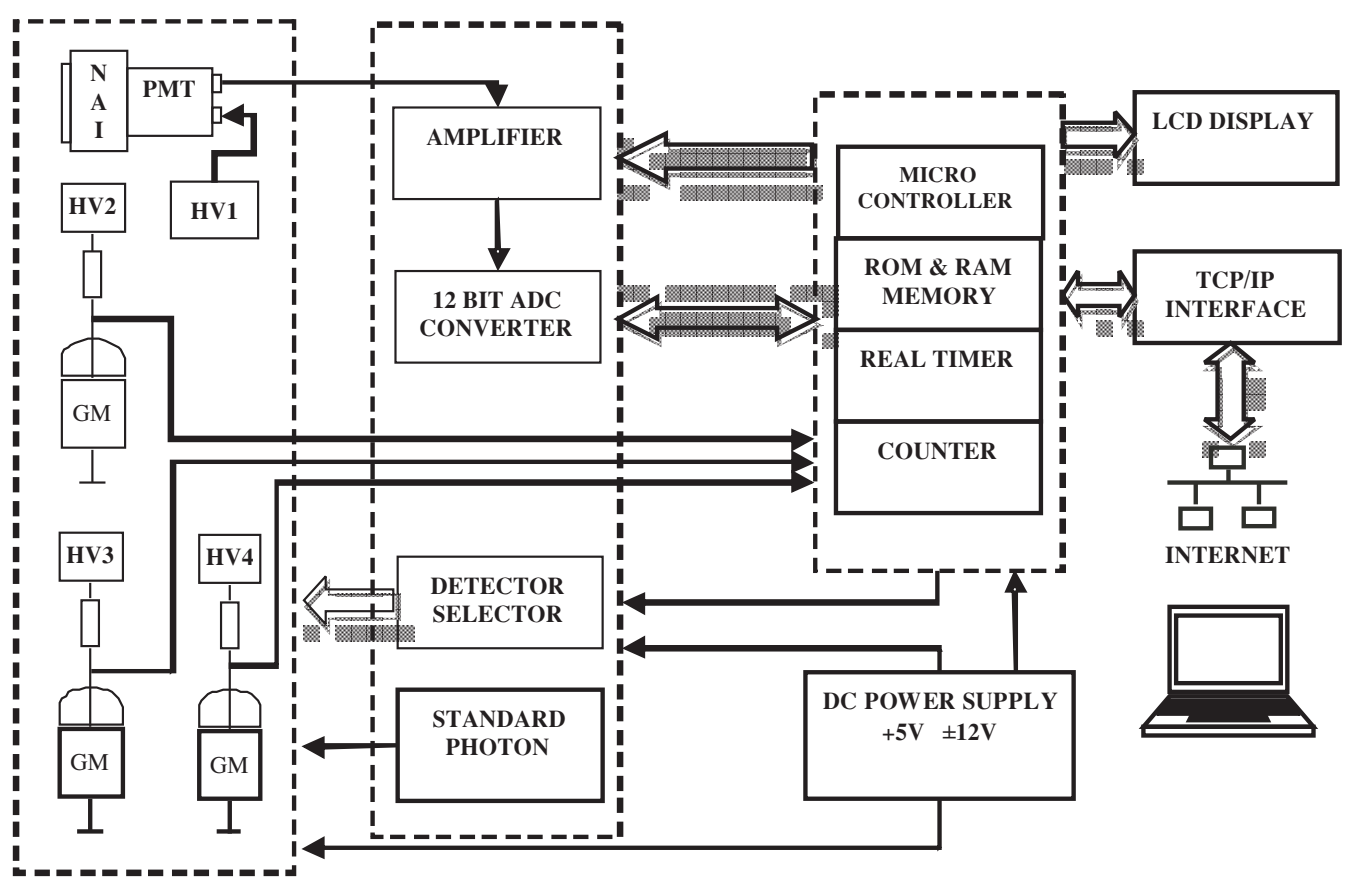

Fig. 1. Block Diagram of the EWRMS 
Table 1. Probe selections and corresponding ranges of dose rate

\begin{tabular}{|c|c|c|}
\hline No. & Probe selection & Dose range \\
\hline 1 & NaI(TL) & $0.1 \mu \mathrm{Sv} / \mathrm{h}$ to $25 \mu \mathrm{Sv} / \mathrm{h}$ \\
\hline 2 & GM1 & $25 \mu \mathrm{Sv} / \mathrm{h}$ to $250 \mu \mathrm{Sv} / \mathrm{h}$ \\
\hline 3 & GM2 & $250 \mu \mathrm{Sv} / \mathrm{h}$ to $1 \mathrm{mSv} / \mathrm{h}$ \\
\hline 4 & GM3 & $1 \mathrm{mSv} / \mathrm{h}$ to $100 \mathrm{mSv} / \mathrm{h}$ \\
\hline
\end{tabular}

\section{Software Design}

The software, running on Philip microcontroller 89C51RD2, controls all operations of the instrument and calculates the dose from the measured gamma spectrum. It is written in C programming language Keil. A flow-chart is shown in Figure 2. The program performs the following tasks:

Start ADC and store data in RAM for each time cycle.

Calculate and convert measured gamma spectrum to doses, display result on LCD and store data in memory.

Process spectrum and identify origin of radiation incident.

Transmit warning alarms and related information to the monitoring centre via Internet.

Each time cycle measure the reference light source signal and adjusts the amplifier gain accordingly.

The interface with the computer is written by in LabView, allowing for data monitoring as well as for sending commands to control the instrument.

\section{CONVERTING THE PULSE HEIGHT SPECTRUM INTO DOSES}

The gamma ray flux, its composition and associated exposure rates are obtained from the pulse height spectrum measured using the $\mathrm{NaI}(\mathrm{Tl})$ scintillation detector. The exposure rate $X$ is related to the spectrum through the following relation:

$$
X=\int_{E_{\min }}^{E_{\max }} N(E) G(E) d E=\sum^{I_{\max }} N(I) G(I)
$$

where $N(E)$ measures the pulse height spectrum in cpm per keV and $N(I)$ in cpm per channel, $E$ being the pulse height in $\mathrm{keV}$ and $I$ the channel number; $E_{\min }$ is the pulse height threshold $(\mathrm{keV}), E_{\max }$ is the maximum energy for the exposure rate evaluation $(\mathrm{keV}), I_{\min }$ is the channel number corresponding to $E_{\min }, I_{\max }$ is channel number corresponding to $E_{\text {max }}, G(E), G(I)$ are the spectrum-to-dose conversion operators.

$G(E)$ can be expressed as a sum of polynomials:

$$
G(E)=\sum_{K=1}^{K \max } A(K) \cdot\left\langle\log _{10}(E)\right\rangle^{K-M-1}
$$

where $A(K)$ are coefficients to be determined. In the case of a $1 " \times 1$ " $\mathrm{NaI}(\mathrm{Tl})$ crystal, they are given in Table 2 with $\mathrm{K}_{\max }=20$ and $\mathrm{M}=3$. 


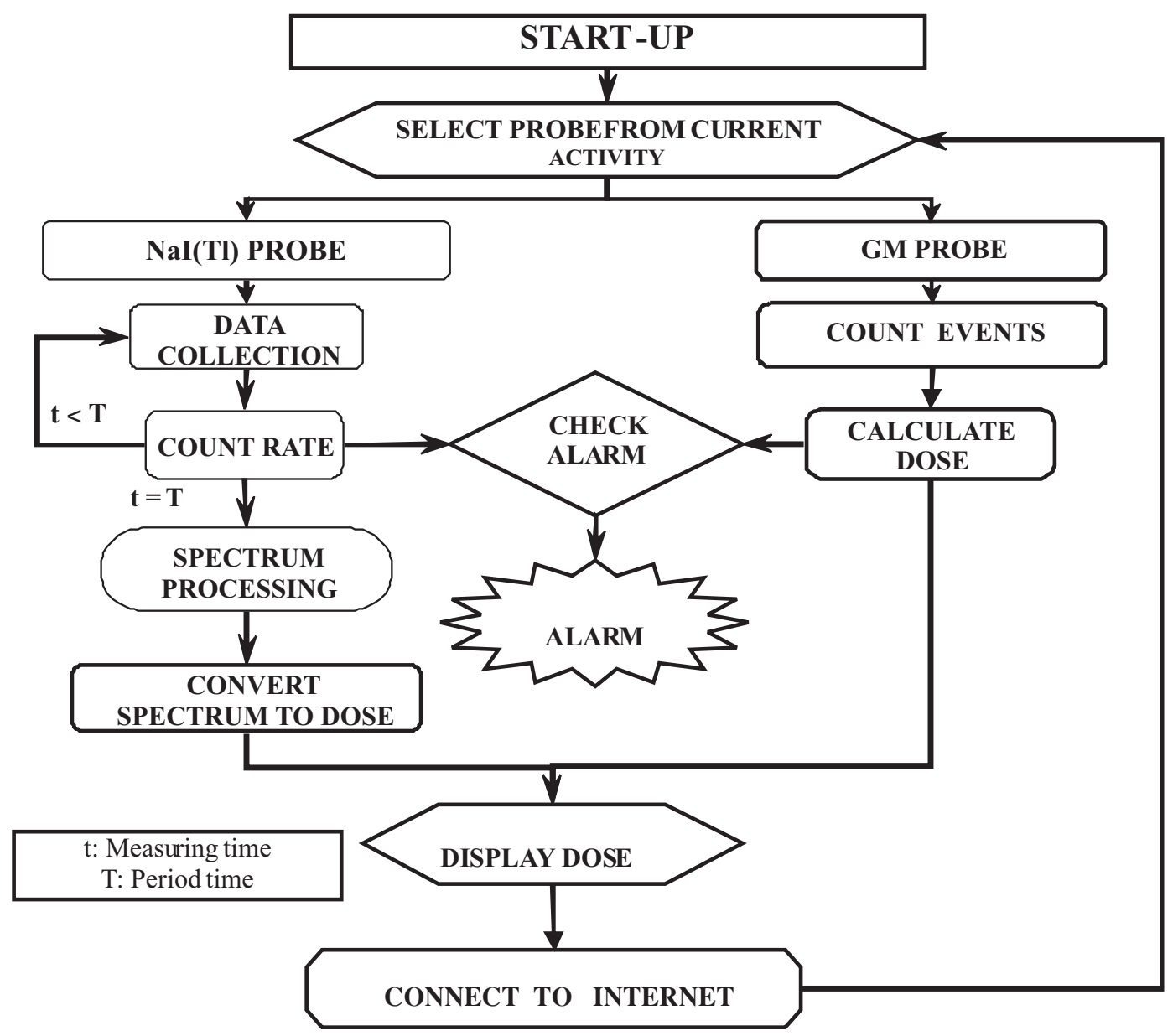

Fig. 2. Flow-chart of the program

\section{RESULT AND DISCUSSION}

An EWERMS prototype has been constructed (Fig. 3).

The detectors have been calibrated at the Secondary Standards Dosimetry Laboratory (SSDL) of the Institute for Nuclear Science and Technology for a dose rate range from $0.7 \mu \mathrm{Sv} / \mathrm{hr}$ to $20 \mathrm{mSv} / \mathrm{hr}$. The result, displayed in Figure 4, implies an uncertainty of $\pm 15 \%$ that is within acceptable standard.

The instrument, when used within environmental ONLINE radiation monitoring and early warning networks, will provide essential benefits and important information in case of possible locally detectable radiation incidents. It provides measurements of the radiation levels and origin of radiation.

Its benefits are:

Early detection of abnormal environmental radiation situation;

Supports to identify the origin of radiation incident; 
Table 2. Values of $A(K)$

\begin{tabular}{|c|c|c|c|}
\hline $\mathbf{A}(\mathbf{K})$ & $\mathbf{K}_{\max }=\mathbf{2 0}, \mathbf{M}=\mathbf{3}$ & $\mathbf{A}(\mathbf{K})$ & $\mathbf{K}_{\max }=\mathbf{2 0}, \mathbf{M}=\mathbf{3}$ \\
\hline $\mathrm{A}(1)$ & $1.49275099570029 \mathrm{E}+03$ & $\mathrm{~A}(11)$ & $-1.15787023098615 \mathrm{E}+00$ \\
\hline $\mathrm{A}(2)$ & $-2.91658773780102 \mathrm{E}+03$ & $\mathrm{~A}(12)$ & $8.94041702581576 \mathrm{E}-01$ \\
\hline $\mathrm{A}(\mathbf{?} ?)$ & $1.15926424258823 \mathrm{E}+03$ & $\mathrm{~A}(13)$ & $7.87239563912950 \mathrm{E}-01$ \\
\hline $\mathrm{A}(4)$ & $1.14140418958232 \mathrm{E}+03$ & $\mathrm{~A}(14)$ & $-3.03009156457287 \mathrm{E}-01$ \\
\hline $\mathrm{A}(5)$ & $-1.01302040986778 \mathrm{E}+03$ & $\mathrm{~A}(15)$ & $-7.62288782837513 \mathrm{E}-02$ \\
\hline $\mathrm{A}(6)$ & $9.08322216928152 \mathrm{E}+01$ & $\mathrm{~A}(16)$ & $5.27880449195923 \mathrm{E}-02$ \\
\hline $\mathrm{A}(7)$ & $1.23704377416037 \mathrm{E}+02$ & $\mathrm{~A}(17)$ & $-6.90413288198483 \mathrm{E}-03$ \\
\hline $\mathrm{A}(8)$ & $-5.14679285896588 \mathrm{E}+01$ & $\mathrm{~A}(18)$ & $-7.33025657836061 \mathrm{E}-04$ \\
\hline $\mathrm{A}(9)$ & $3.02223431771800 \mathrm{E}+01$ & $\mathrm{~A}(19)$ & $2.45581452872742 \mathrm{E}-04$ \\
\hline $\mathrm{A}(10)$ & $-1.28281664110684 \mathrm{E}+01$ & $\mathrm{~A}(20)$ & $-1.62008901437124 \mathrm{E}-05$ \\
\hline
\end{tabular}

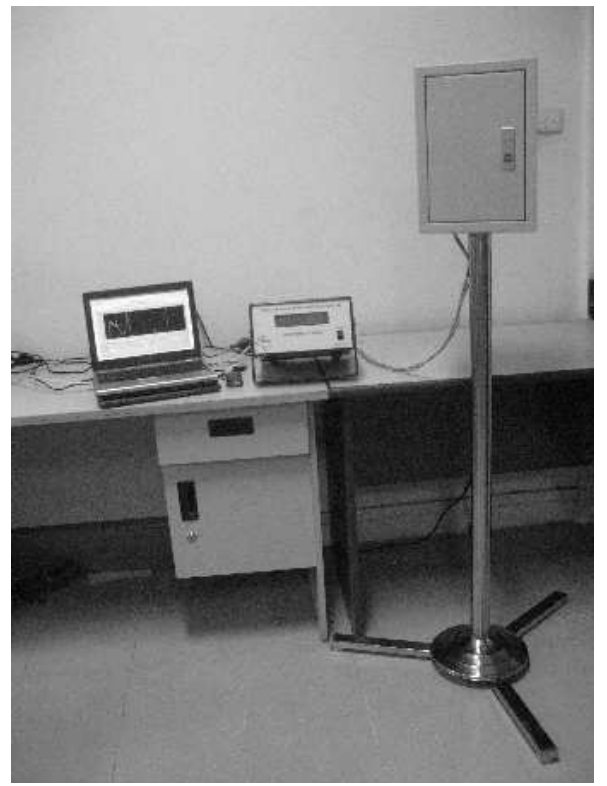

Fig. 3. Pototype monitoring station, including the radiation detectors in a metal enclosure and the interface.

Low TCO (Total Cost of Ownership) due to low investment, highly automated operation, very low maintenance, remote configuration and control capabilities.

\section{CONCLUSION}

Measurements of ambient dose rates are required for the establishment of a national data base, the continuous monitoring of the environmental radioactivity and the prompt detection of imporatnt and/or sudden changes. Monitoring stations are being constructed 


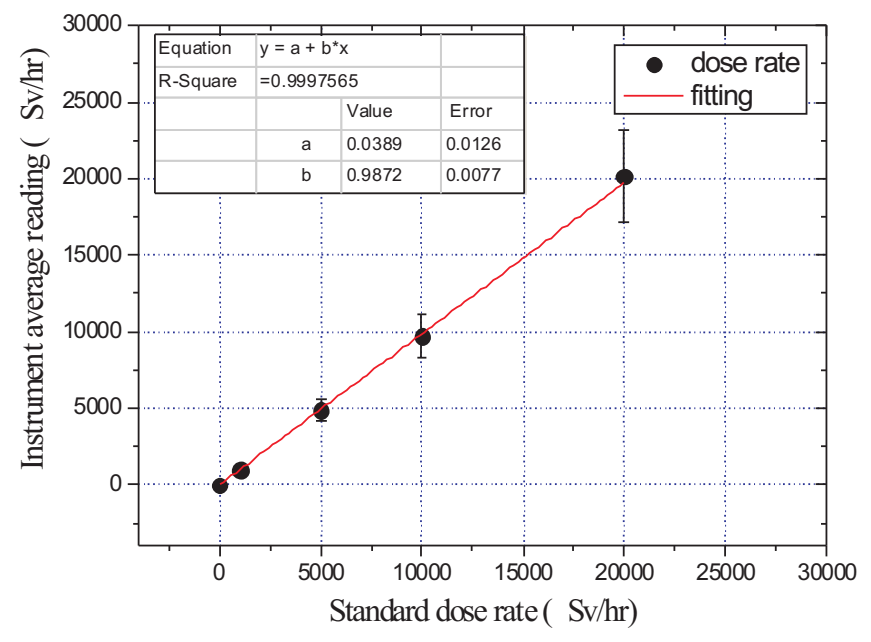

Fig. 4. Dose rate calibration $\mu \mathrm{Sv} / \mathrm{hr}$ as measured up to $20 \mathrm{mSv} / \mathrm{hr}$.

for this purpose, based on simple detectors (a radiation detector together with extra environmental sensors). The high cost of commercially available detectors calls for conceiving a low cost design. The present EWERMS prototype addresses this need with the aim to produce a reliable low-cost instrument. It can also be used for many other applications in the domain of radiation monitoring and radiation safety. The construction and operation of the present prototype has demonstrated its feasibility as a home made, low consumption and low cost instrument that conforms to standards.

\section{ACKNOWLEDGMENT}

We are deeply indebted to the Institute of Nuclear Science and Technology, Vietnam Atomic Energy Institute and Ministry of Science Technology for their support.

\section{REFERENCES}

[1] H.L. Beck, W.J. Condon, and W.M. Lowder, Spectrometric Techniques for Measuring Environmental Gamma radiation, USAEC Report HASL-150, October (1964).

[2] T. Nagaoka, Radiat. Prot. Dosimetry 18 (1987) 81.

[3] G. Cho, H. K. Kim, H.Woo, G.Oh and D.K. Ha, IEEE Transaction on Nuclear Science 45 (1998) 981.

[4] G. Fehrenbacher, Method for the Spectrometric Photon Dosimetry for X-ray and Gamma Radiation. Patent Application Publication, Pub. No: US2009/0127468A1, Pub. Date: May 21, 2009.

[5] Takao Tojo, Nucl. Instrum. Meth. 205 (1983) 517.

[6] S.A. Philips, F.Bronson, R. Venkataraman and B.M. Young, ISOCS Characterization of Sodium Iodide Detector for Gamma-ray Spectrometry. Nuclear Science Symposium Conference Record, 1 (2004) 211

[7] K. Saito and S. Moriuchi, Nucl. Inst. Meth. 226 (1984) 449.

[8] M. Tsutsumi, K.Saito and S. Moriuchi, J Nucl Sci Technol. 37 (2000) 300. 
[9] D.A. Rasolonjatovo, H. Suzuki, N. Hirabayashi, T. Nunomiya,T. Nakamura and N. Nakao, J. Radiate. Res. 43 (2002) S27-33.

[10] C.Holzheimer and S.Hartmann, SARA (Spectroscopic Ambient Radiation Detection) Spectroscopic Monitoring Systems for online Environmental Radiation Monitoring Edition 2008, Proceeding of IX Radiation Physics 85 Protection Conference, 15-19 November 2008, Nasr City- Cairo, Egypt.

[11] Inspector 1000, Digital Hand-held MCA, User's Manual.

[12] LB 125 - Analyzer version 1.47, Berthold Operating Manual.

Received 05 September 2011. 